\title{
Happiness, Environment and Wealth: What Can Bhutan Show Us about Resolving the Nexus?
}

\author{
Dorji Yangka*, Peter Newman \\ Curtin University Sustainability Policy (CUSP) Institute, Curtin University, Perth, Australia \\ Email: *dorjlhen@gmail.com
}

How to cite this paper: Yangka, D. and Newman, P. (2019) Happiness, Environment and Wealth: What Can Bhutan Show Us about Resolving the Nexus? Modern Economy, 10, 1851-1871. https://doi.org/10.4236/me.2019.108120

Received: November 1, 2018

Accepted: August 20, 2019

Published: August 23, 2019

Copyright ( 2019 by author(s) and Scientific Research Publishing Inc. This work is licensed under the Creative Commons Attribution International License (CC BY 4.0).

http://creativecommons.org/licenses/by/4.0/ (c) (i) Open Access

\begin{abstract}
The Environmental Kuznets Curve hypothesis examines how economic development can improve environmental outcomes (called Ecological Modernisation Theory) or it can cause worse outcomes (called Treadmill of Production Theory). This paper examines Bhutan which has committed policies for increased happiness and wealth while remaining carbon neutral. The difference is being tested by regression analysis of how economic growth varies with the environmental intensity of well being (EIWB). The regression analysis shows that the case of Bhutan can be explained in terms of the Treadmill of Production Theory based on economic and wellbeing growth harming the environment, however, it is simply too early in the EKC. The data also show that population growth helps resolve the nexus which works more in the Ecological Modernisation Theory perspective and supports the need to continue urbanization to resolve these issues. Rather than just simply waiting for economic growth to turn around the EKC, Bhutan should take direct action to maintain its carbon neutral goal and its happiness goal and thus continue to provide a model for the sustainable development discourse in general. Highlights: 1) The concept of the environmental intensity of human well being (EIWB) was used to examine the two dominant environmental impact theories: Treadmill of Production Theory (TPT) under the IPAT hypothesis and Ecological Modernisation Theory (EMT) for Bhutan under the framework of the EKC hypothesis. 2) The nexus between economic growth and EIWB leans towards TPT, but it is still too early to see EKC though decoupling has begun and is likely to lead to EMT. 3) The nexus between population and EIWB leans towards EMT. 4) The need for intervention on social and environmental issues within a modified economic growth trajectory remains the core finding of how sustainable development can be achieved.
\end{abstract}

\section{Keywords}

Bhutan, Carbon Neutral, Happiness, Wellbeing, Environment, 
Economic Growth, Regression Analysis, Environmental Kuznets Curve

\section{Introduction}

In the era of the Sustainable Development Goals (SDG's) and the Paris Agreement on Climate Change, the world is struggling to find how to resolve the nexus between the need for economic growth and human happiness to be enhanced while living within environmental limits such as climate change. Three approaches to these issues are common in the past whether commentators come from three disciplinary bases: an economist's perspective where economic growth is always optimised [1] [2] [3] [4], an environmental scientist's perspective where environmental outcomes are always optimised [5] [6], and a human wellbeing perspective where that is always optimised [7] [8] [9].

Despite the sustainable development discourse which tries to integrate all three, there is a strong reaction in the literature that keeps these three strands separate with little attempt to resolve how they can be integrated. The gap between these approaches seems to be widening; for example, a special volume on "Absolute Reductions" in the Journal of Cleaner Production [10] emphasised the need for a radical socio-technical transformation that can bring material, energy and emissions within ecological limits. In order to do this, economic activities were seen to be at the heart of the problem as consumption drives all the problems and this is increased by economic growth [11] [12]. This is the degrowth movement and below this is expanded to show it is being described as the Treadmill of Production Theory.

The alternative approach to economic growth suggests that economic growth can also (eventually) be the driver of changes that lead to decreases in the flow of energy and emissions through technology that becomes more affordable and more politically acceptable as development occurs [13] [14] [15]. The tool used to describe this approach is the Environmental Kuznets Curve (EKC) hypothesis. This tool is widely used to help explain economic-environmental trade-offs, some studies supporting it while others contrasting it and some others finding mixed results (see Section 2). The EKC will be developed further below as the basis of the Ecological Modernization Theory. This literature does not include social issues in the triple bottom line nexus but now there is an emerging research strand that tests the EKC by investigating the nexus between economic growth and the environmental intensity of human well being (EIWB) [16] [17] or carbon intensity of human well being (CIWB) [18] [19].

This study follows the emerging research strand by applying it to Bhutan. Using a regression analysis, the paper attempts to examine the case of Bhutan to see if the nexus between these three factors can be resolved and shed light on how an emerging nation may need to address the overlap behind these issues. Bhutan has pledged to remain carbon neutral while it pursues its famous Gross National Happiness $(\mathrm{GNH})$ strategy for a more holistic development outcome whilst 
growing economically to be a middle range income country [20] [21]. The case of Bhutan has potential to shed further light on this complex nexus because it has clear positions on all three areas of happiness $(\mathrm{GNH})$, environment (carbon neutrality) and wealth (GDP).

Bhutan's three goals are quite clearly specified:

1) Happiness, as defined by the Bhutan GNH, is about maintaining a symbiotic relation with nature and balancing material and non-material components of human well being; this is committed by Bhutan to be continually growing [20] [22].

2) Bhutan has pledged to remain carbon neutral in perpetuity which is to have net zero carbon emissions [23].

3) Bhutan wants as well to be a middle income country by 2023 whilst pursuing its GNH strategy.

This suggests that the goals of Bhutan are complex and challenging-requiring the integration of socio-economic and environmental dimensions which are at the heart of Bhutan's GNH development philosophy and is increasingly associated with Sustainable Development [24] [25] [26]. However, until now no empirical studies exist for in-depth Bhutan-specific studies on the nexus between economic growth, human well being and environmental pollution, though a possibility of research on linking subjective well being and ecological footprint has been mentioned [27]. Some studies [28] [29] have included Bhutan in their cross-national level research on issues to do with development and footprint.

Thus, this paper attempts to fill this gap on Bhutan by using the concept of environmental intensity of human well being (EIWB) [16] [30] [31] to understand using data the various different conjectures about the nexus between happiness, wealth and the environment. It is hoped that the detailed study of an emerging nation can help the rather conflicted debates that are occurring about these three factors. This will have implications on the contested sustainability discourse especially in light of the Paris Agreement and the United Nations Sustainable Development Goals (SDG) for other emerging nations.

\section{Environment and Economic Growth Theories}

In the era of the SDGs and the Paris Agreement, the level of GHG emissions is a key environmental issue, which is perhaps the greatest environmental issue being faced by humanity in the $21^{\text {st }}$ century. However, there are two strongly divergent theories about how to explain the relationship: Ecological Modernisation Theory which is based on a strongly positive acceptance of GDP-based economic growth as helping resolve issues of wealth and the environment and Treadmill of Production Theory which sees GDP-based economic growth as fundamentally causing environmental issues through its link to the IPAT formula.

\subsection{Ecological Modernisation Theory}

Ecological Modernisation Theory (EMT) has been using mainstream economic development theory to include how and when environmental factors are brought 
into the mainstream of development. EMT was developed by Joseph Huber [32] and the central tenet is to explore institutional reforms and technological advancement to mitigate ecological crises of modernity [33] [34]. EMT uses the Environmental Kuznets Curve (EKC) as the main tool to explain the evolving relationship between environmental quality and the economic development for a country or countries. The EKC tool was first developed by Panayotou [35]. The EKC suggests that an inverted U-shaped curve best explains how economic growth relates to the environment with a certain minimum in growth being required before environmental outcomes start to peak and then decline [35] [36]. The EKC literature has been growing dramatically [37] [38] suggesting the importance of and the interest to understand the environmental impact of economic development with which the world is still grappling.

Studies to test EKC theory were analysed using regression analysis on time series and cross-sectional data. For instance, Song et al. [39] used an Ordinary Least Square estimation for a cubic log-log model to assess EKC in the provinces of China between GDP per capita and the three environmental degradation parameters of waste water, solid waste and waste gas and found the EKC could explain all three. Similarly, Riti et al. [40] also found evidence of EKC for $\mathrm{CO}_{2}$ emissions and economic growth in China using various regression techniques. Al-mulali et al. [41] conducted multi-variant regression to examine EKC in 93 countries using ecological footprint as environmental variable and showed that the EKC holds for high incomes countries but not for low income countries. Similarly EKC was found for 10 Middle East and North African countries [42] and for a group of 132 countries [43]. EKC was also confirmed by using ecological footprint in place of carbon emissions as the environmental impact parameter [44].

Other studies have demonstrated six different relationships besides the inverted U-shaped curve between economic growth and environmental pollution [45]. Pérez-Suárez and López-Menéndez [28] examined the EKC puzzle and the forecasting ability of the EKC equation for 175 countries (including Bhutan). They added a third degree polynomial term of GDP per capita to extend the existing EKC equation and they found different patterns of EKC, while that for Bhutan along with other 10 countries were classified under "other cubic pattern" of EKC, a pattern other than the typical U-shaped, inverted U-shaped, $\mathrm{N}$-shaped, or inverted $\mathrm{N}$-shaped curves. The present study will explore whether Bhutan exhibits this pattern when examining the nexus between CIWB and economic growth.

The EKC has been used to support the need for economic growth in emerging nations as the basis not just of poverty reduction but also environmental improvement, especially if it is connected to urbanization [46]. The evidence from Asia is very supportive of this, particularly China and has been used to generate support for such urbanization-related economic growth. The Asian Development Bank [47] has shown that Asian countries are significantly earlier in their inverted U-shaped curve and this can be attributed mostly to faster and denser 
urbanisation; in later years Asia also has higher levels of renewable energy. Similarly, Jamel and Derbali [48] have shown that urbanisation in selected Asian countries had a statistically significant negative relation to carbon emissions. Zhang et al. [49] found that the EKC could be established between urbanisation and carbon emissions for 141 countries; this was attributed to urban agglomeration economies that improve the economy and environmental outcomes through economies of scale and density. Similarly, Lin et al. [50] have shown that economic growth in non-high income countries will decrease carbon emissions and even accelerating urbanisation will lead to just small increases in carbon emissions. Wang et al. [51] have shown that urbanisation, income and energy efficiency can allow China and India to pursue economic development without growth in emissions.

\subsection{Treadmill of Production Theory (TPT)}

The TPT was first proposed by Schnaiberg in 1980 [52], based on political economy whereby a capitalistic system becomes like a treadmill creating social and environmental impacts without integrating ways to deal with such issues. Thus, TPT calls for fundamental changes to the economic system rather than just reform and mostly people in this tradition see GDP as a short hand for capitalism [53]. The TPT also now incorporates a more biological approach developed by a number of scientists pioneered by Ehrlich and Holdren (1992); they began to try and explain environmental impact using the formula $\mathrm{I}=\mathrm{PAT}$. This is a combination of Population, Affluence measured as GDP per capita and Technology measured as impact per unit of GDP. GDP is used in this approach to be short for consumption. Quantitative discussions in this approach have been used to show that global impact is likely to continue to increase as long as population and GDP continue to grow [54] [55]. This has been criticised as not understanding that GDP covers much more than consumption, not being able to distinguish the multiple interactions between PAT, not including social change or political change as factors in environmental impact and not doing justice to spatial factors and agglomeration economies as in the EKC and the EMT approach [56] [57] [58].

The EMT suggests that rising economic opportunities will enhance technological advancement and their combination leads to reduced environmental impact once a certain minimum economic growth level is reached. The TPT, however, suggests that economic growth and technological advancement inevitably accelerate resource consumption-the treadmill-leading to further environmental degradation. The two theories are said to be opposing and orthogonal to each other [59].

\subsection{Research Supporting EMT or TPT or Both}

Research on the effect of population on carbon emissions found it was not simply population but was dependent on household size and age structure [60]; others have found more than a proportional impact of population on carbon 
emissions [55] [61], though Dietz and Rosa [61] found that carbon emissions tended to decline at a per capita GDP of US $\$ 10,000$ as would fit with the EKC approach and thus EMT. At national level, Zhang et al. [62] interpreted EMT for china and its relevance to the rapid socio-economic growth experienced by China in the past decade. At a household level, modest support for EMT was found but strong support for TPT was observed also [63]. For Bhutan, it was found that income and education can lead to choosing cleaner energy [64], which in turn can reduce emissions. This supports EMT especially from consumer behaviour and technological choices, though the study was not analysed under the EMT and TPT perspectives. Renewable energy sources make up cleaner forms of energy and it was found to suit the logics of EMT [65].

At the microeconomic level such as business and firms, the Porter hypothesis [66] [67] argues that environmental regulation can trigger technological innovation to reduce impact; this approach has led to the phenomenon of decoupling. The decoupling agenda and green growth are closely associated with Ecological Modernisation Theory. Szigeti et al. [68] found decoupling between ecological footprint and GDP in $90 \%$ of the 131 countries examined. Evidence of economic growth decoupling from greenhouse gas emissions were observed globally [13] [69]. However, Ewing [70] and Jackson [11] argue that green growth postulated by EMT should be rejected as a way to restore environmental degradation evident from climate change and biodiversity loss due to rebound effects.

York et al. [29] employed an Ordinary Least Square analysis under the STIRPAT framework (a flexible version of IPAT), and found a positive effect of both population and economic growth on environmental degradation-supporting TPT and contradicting the expectations of the EMT. They also provided data on the eco-efficiency for 142 nations ranging between 2.76 to 0.52 with smaller values being more efficient and that for Bhutan was reported as 0.75 . Similarly, Dietz and Rosa [61] reported the technology multiplier for 111 nations ranging between 0.24 to 5.75 and that for Bhutan as 0.47 , the smaller value indicating a more environmentally benign socio-economic system. Jorgenson and Clark [71] also found a positive effect of economic growth and population on total carbon emissions and per capita carbon emissions in their cross-national study of 86 countries. Interestingly, they found relative decoupling between economic growth and total carbon emissions but no relative decoupling was observed between economic growth and per capita carbon emissions. Thus, partly supporting both EMT and TPT. This suggests that the unit of measurement can affect the analysis and thereby the outcome of the analysis.

The analyses so far have all been about the nexus between economic growth and environmental outcomes. Now there is an emerging research strand that has applied the EKC hypothesis to incorporate variables that can capture human well being. These are discussed in the next section.

\section{Environment, Economic Growth and Wellbeing}

Applying a regression analysis for cross-sectional data for 107 countries, Jorgenson 
[72] found that economic development leads to increase in carbon intensity of human well being (CIWB) and hence greater environmental impact. Similarly, using a cross sectional data for 135 countries, Dietz et al. [30] showed that increasing environmental impact does not necessarily lead to greater human well being and that the effect of affluence on human well being characterises a diminishing return. A research at province level in China found that economic growth has a positive effect, while technological innovation has non-linear and negative effects on CIWB [73]. This suggests that technological advancement can reduce the environmental stress generated to produce human well being. This is consistent with the expectations of EMT. Similarly, using cross-national data on GDP per capita, subjective well being index and ecological footprint for 105 countries, Knight and Rosa [16] supported the TPT but not the EMT.

Thus from Sections 2 and 3, the existing literature shows that the debate between the Treadmill of Production Theory and Ecological Modernisation Theory remains unresolved. For that matter, the EKC remains unsettled, while it stands as an economic tool for a progressive society. However, there is a clear link between the degree of urbanization and the rate at which the EKC turns around the inverted U-shaped curve [48] [49].

The question in this paper is therefore whether the EKC theories of EMT and TPT can explain the empirical relation for Bhutan that has a clear policy for the three dimensions of sustainability highlighted in Section 1.

\section{Method}

In line with the existing literature, a multivariate regression technique is used to investigate the relationship between human well being, environmental impact and economic growth, arguably capturing the three dimensions of Sustainability. The regression analysis is conducted using EViews, a sophisticated econometrics tool developed with emphasis on time series analysis [74] [75]. This paper used the method deployed by York et al. [29], which was based on the STIRPAT framework, a stochastic version of the IPAT formulation. Robust least square MM estimation ${ }^{1}$ was also used since there were data outliers. The MM estimation was first used by Yohai in 1987 [76]. The MM estimation and the Robust Efficient Weighted Least Square (REWLS) were found to outperform other robust estimation methods [76].

Considering the carbon neutral policy of Bhutan, the present study specifically uses the carbon intensity of human well being (CIWB) in place of the generic EIWB. The CIWB is the ratio between $\mathrm{CO}_{2}$ eq per capita (denoted as $\mathrm{CO}_{2} \mathrm{pc}$ ) and life expectancy (as LE) was used along with population (as pop), and GDP per capita (as GDPpc) representing economic growth. The details on the choice of these variables are discussed in the next section.

${ }^{1} \mathrm{MM}$ estimate is a combination of Maximum likelihood (M) estimate and Scale statistic (S) estimate [75] IHS Global (2014) EViews 9 User's Guide I and II. in IHS Global Inc. (ed.): IHS Global Inc. 


\subsection{The Choice of Variables}

The type of variables used for evaluating the environmental intensity of human wellbeing vary depending on the data availability and scope of the study. For instance, some studies used $\mathrm{CO}_{2}$ emission per capita [18] [72] [73], others have used ecological footprint per capita [16] [30]. Similarly, for human well being, life expectancy was used as a proxy variable in some studies [18] [30] [31], while others have used a life satisfaction index [16]. The choice of variables for the present study was limited by the availability of longer time series data. A longer life expectancy represents healthy living which arguably indicates physical fitness, health services, good food and all other social embedding that impacts longevity. While GDP per capita as a measure of economic growth is well known, the per capita carbon emission is of interest for a carbon-constrained world and for carbon neutral Bhutan. In the present study, per capita $\mathrm{CO}_{2} \mathrm{eq}$ emissions includes GHG emissions from the energy sector, cement production, and from farming and agriculture, thereby capturing most anthropogenic sources of $\mathrm{CO}_{2}$ eq emissions compared to most of the existing research that has accounted for emissions from energy and cement production only [71] [72] [77]. The time series data used in the present study were sourced from the World Bank [78].

\subsection{The Regression Model}

The method based on the STIRPAT framework used in earlier studies [29] [77] [79] was employed to formulate a functional form specified in Equation (1). STIRPAT is flexible and it is being used for hypothesis testing and also the elasticity between the variables can take any value-not restricted to unity as in the IPAT.

$$
\begin{aligned}
\ln C I W B= & C+\beta_{1} \ln G D P p c+\beta_{2}(\ln G D P p c)^{2}+\beta_{3}(\ln G D P p c)^{3} \\
& +\beta_{4} \ln P O P+\beta_{5} \ln C I W B(-1)+\varepsilon_{t}
\end{aligned}
$$

where, $C I W B$ is the ratio variable between $\mathrm{CO}_{2} \mathrm{pc}$ and $\mathrm{LE}$ adjusted for coefficient of variation to reduce the dominance of one variable driving the ratio [72] [73]. $\mathrm{C}$ is the intercept. $\ln G D P p c$ is the per capita GDP in natural logarithmic form and the polynomial terms of GDPpc are centred by subtracting the mean of lnGDPpc to reduce collinearity [16] [18] [29]. It is also logical to add the lag term of the dependent variable as one of the regressors in a time series data analysis- $\ln \mathrm{CIWB}(-1)$ for the present study. POP is the population and $\varepsilon$ is the error term that captures those unobserved explanatory variables. Finally, $\beta_{1}$ to $\beta_{5}$ are the coefficients of the corresponding explanatory variables that are of primary interest in this study, which are to be estimated by regressing Equation (1) using EViews.

On regressing Equation (1) it was found to have serial correlation and very high variance inflation factor (VIF) and also the linear term and the quadratic term of the GDPpc were found to be less significant than the cubic term despite 
being jointly significant as per the Wald test. This led to constructing two reduced form models: without the quadratic term (Equation (2)) and without the linear term (Equation (3)).

$$
\ln C I W B=C+\beta_{1} \ln G D P p c+\beta_{2}(\ln G D P p c)^{3}+\beta_{3} \ln P O P+\beta_{4} \ln C I W B(-1)+\varepsilon_{t}
$$

$\ln C I W B=C+\beta_{1}(\ln G D P p c)^{2}+\beta_{2}(\ln G D P p c)^{3}+\beta_{3} \ln P O P+\beta_{4} \ln C I W B(-1)+\varepsilon_{t}$

Small models with fewer parameters were preferred over large models to reduce parameter uncertainty [80]. Between 2) and 3), we chose model 3) which scores relatively better in most of the model selection criteria. It has higher adjusted $\mathrm{R}^{2}$ and lower Akaike info criterion (AIC), Hannan-Quinn criteria (HC); lower VIFs, and lower SE of regression and standard error for the estimated coefficients. In Equation (3), the quadratic- and the cubic-term were jointly significant at $5 \%$ significance level as per Wald test though the quadratic GDPpc was significant at $25 \%$ significance level only. The joint significance is important here as argued by Brown and McDonough [81]. Moreover, this is within the significance level up to $25 \%$ argued by Agung [80] for cases where a theoretically important variable became statistically insignificant. Furthermore, statistical analysis is considered partly a science and partly an art [82] requiring trial and error methods. In keeping with this, interpretation of the results in the next section requires caution and it is valid within the data set used in this study.

\subsection{Statistical Tests}

For regression analysis, stationarity of data is essential to avoid any spurious regression. In this study, any presence of unit root for all the variables were tested by using the Augmented Dickey Fuller unit root test and Kwiatkowski-Phillips-Schmidt-Shin (KPSS) stationarity test. They were found to be non-stationary at levels but stationary in first difference. However, if the residual from their regression is stationary, then their combination can be considered stationary [81] [82] [83]. This condition was fulfilled in this study-that is the regression results were not spurious.

Statistical tests were conducted on Equation (3). The VIFs were below 16 [84] and it is not reasonable to remove variables just to improve the VIF [82]. The tests for the presence of serial correlation and heteroskedasticity were conducted using the Breusch-Godfrey (BG) LM test and Breusch-Pagan-Godfrey (BPG) test respectively [75] [85]. The p-values failed to reject the null hypothesis of no serial correlation and homoskedasticity. The robustness of Equation (3) was also checked through a robust least squares MM estimation confirming the signs of the explanatory variables with small differences for the values of the estimated coefficients and their associated standard errors.

\section{Results and Discussions}

The estimated equation is provided in Equation (4) with standard errors in pa- 
renthesis. It has an overall goodness of fit (i.e. $\left.R^{2}\right)$ is 0.72 .

$$
\begin{array}{ccc}
\ln C I W B=10.70+0.060 *(\ln G D P p c)^{2}+ & 0.374 *(\ln G D P p c)^{3} & -0.737 * \ln (\text { pop })+0.505 * \ln C I W B(-1) \\
(0.051374) & (0.148765) & (0.284199)
\end{array}
$$

The regression result is shown in Table 1.

The estimated equation illustrates that the relation between the CIWB and GDPpc are positive and curvilinear and that with population is negative. The relationship between CIWB and GDPpc is shown in Figure 1.

The pattern shown by Figure 1 appears to concur with the 'other cubic pattern' observed in earlier study [28] considering that the cubic GDPpc term in Equation (4) is highly significant. Equation (4) suggests that Bhutan is both supporting the TPT (the GDP result) and the EMT (the population result). These findings are elaborated in the following sections.

\subsection{Discussion on the GDP Result}

The result of GDPpc causing greater carbon intensity per unit of well being suggests that GDP is not (yet) helping with the social and environmental issues associated with development in Bhutan as outlined in the TPT. The coefficient of the quadratic GDPpc was comparable with that reported in a cross national data [29]. Thus GNH or at least the existing socio-economic pattern appears to be leading to greater carbon intensity in Bhutan because enhancing human well being follows a significantly positive and curvilinear relationship with economic growth. And the economic growth has not yet reached a level where the EKC curve would suggest that economic growth will start to reduce carbon intensity. Thus, at this juncture in Bhutan's growth trajectory, the current per capita GDP for Bhutan is far below the various threshold levels reported in the literature suggested before the EKC turns around on the inverted $U$ curve and begins to decline $^{2}$. The way ahead for Bhutan which is seeking to resolve the three factors of wealth, happiness and the environment, is therefore quite complex.

The evidence from Bhutan is that the transition to reduced carbon intensity of well being is not yet under way. In other words, the result supports the Treadmill of Production Theory. The result reflects the transitioning of the Bhutanese economy from agriculture-based economy to manufacturing and industrial-based economy [86] [87]. The latter being more polluting than the former. To avoid environmental degradation in the early stage of development, Panayotou [35] suggests that environmental protection should be an integral part of development plans especially in developing countries. For Bhutan with its GNH strategy this had always been the objective and it cannot be stressed more especially now with its carbon neutral pledge that Bhutan will need to bend the emission curve before other nations have managed to do this.

${ }^{2}$ The average threshold value was found to be United States Dollar (US\$) 8910 as per the meta-analysis conducted by [38] Sarkodie, Samuel Asumadu and Vladimir Strezov (2019) A review on Environmental Kuznets Curve hypothesis using bibliometric and meta-analysis. Science of The Total Environment, 649: 128-145. 
Table 1. EViews result.

Dependent Variable: $\ln (C I W B)$

Method: Least Squares

Date: 07/07/18 Time: 20:55

Sample (adjusted): 19812012

Included observations: 32 after adjustments

\begin{tabular}{ccccc}
\hline Variable & Coefficient & \multicolumn{1}{l}{ Std. Error } & t-Statistic & \multicolumn{1}{c}{ Prob. } \\
\hline C & 10.70163 & 3.984600 & 2.685747 & 0.0122 \\
$(\ln G D P p c)^{2}$ & 0.060291 & 0.051374 & 1.173556 & 0.2508 \\
$(\ln G D P p c)^{3}$ & 0.374333 & 0.148765 & 2.516265 & 0.0181 \\
$\ln (P O P)$ & -0.737654 & 0.284199 & -2.595550 & 0.0151 \\
$\ln (C I W B(-1))$ & 0.505066 & 0.158513 & 3.186272 & 0.0036 \\
$R^{2}$ & 0.725492 & Mean dependent var & 1.934224 \\
Adjusted $R^{2}$ & 0.684824 & S.D. dependent var & 0.121036 \\
S.E. of regression & 0.067950 & Akaike info criterion & -2.397477 \\
Sum squared resid & 0.124666 & Schwarz criterion & -2.168456 \\
Log likelihood & 43.35964 & Hannan-Quinn criter. & -2.321563 \\
F-statistic & 17.83940 & Durbin-Watson stat & 1.835457 \\
Prob(F-statistic) & 0.000000 & & \\
\hline
\end{tabular}

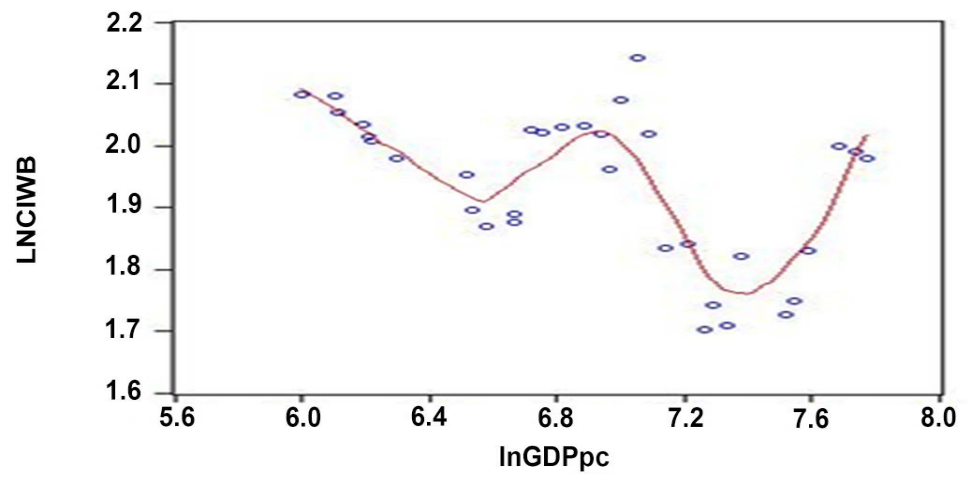

Figure 1. CIWB plotted against GDP/capita.

One way to examine if the EKC is perhaps beginning in a developing country is to examine if relative decoupling of wealth and environmental impact has begun. Developing countries with low GDP have been found to exhibit relative decoupling [88]. Bhutan's GDP seems to exhibit a relative decoupling from $\mathrm{CO}_{2}$ eq emissions as shown in Figure 2, although this was not the case for carbon intensity of well being. This suggests that there is a need to enhance life expectancy (the denominator of the CIWB) considering that the LE ranges from 45 years in 1980 to just 68 years in 2012. Moreover, Bhutan is still in its early stages of socio-economic development thus struggling to enhance liveability conditions for its citizenry. 


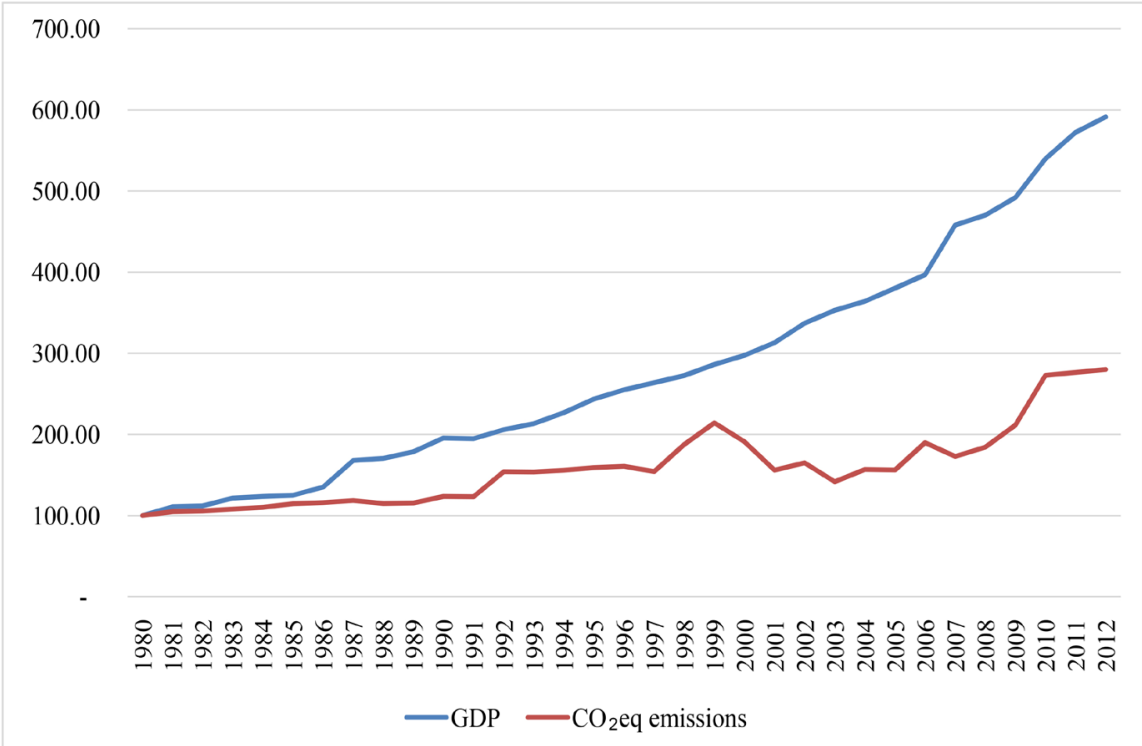

Figure 2. Economic growth and $\mathrm{CO}_{2}$ eq emissions (based on data source: World Bank [78].

This calls for greening Bhutan's socio-economic activities in line with the aspiration of GNH and carbon neutral emphasised in their $12^{\text {th }}$ five-year plan [89] and their economic development policy [90] [91]. The need to further green growth in Bhutan was also emphasised by the World Bank [92]. It can be expected that economic growth in middle-income countries will decrease carbon emissions [50] but it needs action sooner to be consistent with its global commitments to happiness and carbon neutrality.

\subsection{Discussion of the Population Result}

If the TPT approach had been the dominant story with Bhutan then the coefficient of population being negative in Equation (4) would not have been predicted. The result suggests that growing population will help carbon intensity per unit of well being. This finding may seem spurious to the IPAT identity that considers population as the main driver of environmental degradation [5] [29] [61]. Furthermore, the finding contradicts the adverse environmental impact of population growth speculated in the national strategy of Bhutan [93]. One way to explain this in the TPT model is to suggest that it is consumption (GDP) that is over-riding the population factor as Toth and Szigeti [94] found in their studies. However, it is also possible to see within the EMT approach that population growth, if it is in cities, can be an important factor in more rapidly leading to the EKC turn-around that would help Bhutan achieve its multiple goals. Lamb et al. [79] found this to be the case for population growth in their global study, and for the case of China by Zheng et al. [95] and Meng and Huang [96]. The plausibility of this is that in Bhutan farming and agriculture activities, which are concentrated in rural areas, are the major contributors of $\mathrm{CO}_{2} \mathrm{eq}$ emissions for the time 
period prior to 2000 [97]. Rural Bhutan accounts for $66 \%$ of the total population [98].

Thus as wealth and population grow there is a faster move to the city and then a series of other factors follow that may indeed reduce consumption as economies of scale and density create smaller houses, better public transport and other potential impacts on consumption like greater recycling [51] [99] [100] [101]. Bhutan expects its urbanisation rate to increase from $10 \%$ to $51 \%$ in just 55 years compared to 95 years for Asia and 150 years for Europe [47]. This trend can be a positive phenomenon as Bhutan aspires to be a knowledge-based society [91] while also sustaining its carbon neutral goal. Wang [102] argues that rather than focusing on reducing population, the aim should be to educate and create awareness of how to reduce carbon emissions through behaviour changes. Similarly, Costantini and Monni [103] emphasised the need to invest in human and social capital to simultaneously achieve a higher living standard and environmental protection.

From Sections 5.1 and 5.2, it is clear that the case of Bhutan provides support for TPT with regard to GDP as the driver and EMT approach for its population growth that is showing positive outcomes as would be suggested with its rapid urbanization. Furthermore, urban areas were found to be happier [22] and wealthier [98] [104] compared to their rural counterparts. In the interim as it moves towards the top of the inverted U-shaped curve there are appropriate policy interventions that can be put in place so well being and environmental quality are not degraded while the economy grows [105].

\section{Conclusions}

Using established econometric techniques, this study has attempted to interlink the relationships between the carbon intensity of human wellbeing and economic growth as a way of resolving how Bhutan is managing to balance happiness, environment and economic growth. It examined the two main approaches that are being used to explain these interactions: Ecological Modernisation Theory based on the Environmental Kuznets Curve, and Treadmill of Production Theory with its basis on the IPAT model. This study has used a 33-year set of data on Bhutan and through vigorous analysis of the time series data on some of the key variables, it has been able to show the following key conclusions.

1) The case of Bhutan appears to support the Treadmill of Production Theory against the Ecological Modernisation Theory as it is showing that GDP is causing the carbon intensity per unit of wellbeing to get worse. However, this is relatively easy to explain in terms of Ecological Modernisation Theory also as it is simply too early in the EKC curve to begin showing the potential reduction in carbon intensity found in more developed places, when examining the nexus between economic growth, human wellbeing and carbon emissions.

2) While the relationship between CIWB and GDP per capita is curvilinear, the relationship between GDP and carbon emissions does not appear to be in 
lockstep and it seems that relative decoupling is underway. However, there is not yet sufficient economic development for the wellbeing and environmental factors to be more optimised.

3) The case of Bhutan supports the Ecological Modernisation Theory when it examines population growth in that there is a statistically significant negative relation between population and carbon intensity of human wellbeing. It supports the theory of how the EKC turns around after some economic development because it is associated with population growth in cities rather than rural areas and Bhutan is showing all these characteristics.

4) Although Bhutan is still in its early stage of development and aspires to be a middle-income country, it has already pledged to grow in wellbeing and maintain its carbon neutrality. These can only be achieved by decoupling them from the growth in wealth through modifying economic growth to include energy efficiency and decarbonisation policies as well as continuing the commitment to GNH to enable growth in well being.

This research therefore formally places the case of Bhutan into the burgeoning literature on the Environmental Kuznets Curve proposition especially through the lens of the "environmental intensity of human well-being". It suggests that its current growth trajectory is likely to turn around carbon intensity per unit of wellbeing as it moves more towards being a middle-income country. However, it should not wait to intervene on matters concerning the modification of economic growth in order to ensure its commitments to GNH and carbon neutrality are maintained. While this study is the first of its kind for Bhutan, it shows a promising line of research that may further inquire into the socio-technical structure of the Bhutanese economy that can complement the quantitative analysis undertaken in this study and provide a more nuanced picture of how it can balance the three goals. Similarly, other emerging nations that are yet to reach the top of the inverted U-shaped EKC may also seek direct ways to deal with social and environmental issues whilst maintaining their economic growth. Thus by Bhutan maintaining its carbon neutral goal and its happiness goal along with its economic goal, it is likely to continue to provide a model for the sustainable development discourse in general.

\section{Acknowledgements}

The lead author would like to thank the Government of Australia for providing the Research Training Programme (RTP) scholarship and Curtin University for the research top up scholarship (CRS). The authors would like to thank the anonymous reviewer for the comments.

\section{Conflict of Interest}

The authors declare no conflict of interest. The funding sponsors had no role in the design of the study; in the collection, analyses, or interpretation of data; in the writing of the manuscript, and in the decision to publish the results. 


\section{References}

[1] Ayres, R.U. (1998) Towards a Disequilibrium Theory of Endogenous Economic Growth. Environmental and Resource Economics, 11, 289-300. https://doi.org/10.1023/A:1008239127479

[2] Nguyen, M.-H. and Nguyen-Van, P. (2016) Optimal Endogenous Growth with Natural Resources: Theory and Evidence. Macroeconomic Dynamics, 20, 2173-2209. https://doi.org/10.1017/S1365100515000061

[3] Solow, R.M. (1956) A Contribution to the Theory of Economic Growth. The Quarterly Journal of Economics, 70, 65-94. https://doi.org/10.2307/1884513

[4] Stokey, N.L. (1998) Are There Limits to Growth? International Economic Review, 39, 1-31. https://doi.org/10.2307/2527228

[5] Ehrlich, P.R. and Holdren, J.P. (1971) Impact of Population Growth. Science, 171, 1212-1217. https://doi.org/10.1126/science.171.3977.1212

[6] Daily, G.C. and Ehrlich, P.R. (1992) Population, Sustainability, and Earth's Carrying Capacity. BioScience, 42, 761-771. https://doi.org/10.2307/1311995

[7] Turner, B.S. (2018) (I Can't Get No) Satisfaction: Happiness and Successful Societies. Journal of Sociology, 54, 279-293. https://doi.org/10.1177/1440783318774858

[8] Sachs, J. (2012) Introduction. In: Helliwell, J., Layard, R. and Sachs, J., Eds., World Happiness Report. The Earth Institute.

https://www.earth.columbia.edu/sitefiles/file/Sachs\%20Writing/2012/World\%20Ha ppiness\%20Report.pdf

[9] Lyubomirsky, S., Sheldon, K.M. and Schkade, D. (2005) Pursuing Happiness: The Architecture of Sustainable Change. Review of General Psychology, 9, 111-131. https://doi.org/10.1037/1089-2680.9.2.111

[10] Akenji, L., Bengtsson, M., Bleischwitz, R., Tukker, A. and Schandl, H. (2016) Ossified Materialism: Introduction to the Special Volume on Absolute Reductions in Materials Throughput and Emissions. Journal of Cleaner Production, 132, 1-12. https://doi.org/10.1016/j.jclepro.2016.03.071

[11] Jackson, T. (2009) Prosperity without Growth: Economics for a Finite Planet. Earthscan, London. https://doi.org/10.4324/9781849774338

[12] Rockström, J., Steffen, W., Noone, K., Persson, Å., Chapin III, F.S., Lambin, E., Lenton, T.M., Scheffer, M., Folke, C., Schellnhuber, H., Nykvist, B., De Wit, C.A., Hughes, T., van der Leeuw, S., Rodhe, H., Sörlin, S., Snyder, P.K., Costanza, R., Svedin, U., Falkenmark, M., Karlberg, L., Corell, R.W., Fabry, V.J., Hansen, J., Walker, B.H., Liverman, D., Richardson, K., Crutzen, C. and Foley, J. (2009) A Safe Operating Space for Humanity. Nature, 461, 472-475. https://doi.org/10.1038/461472a

[13] Newman, P. (2017) Decoupling Economic Growth from Fossil Fuels. Modern Economy, 8, 791-805. https://doi.org/10.4236/me.2017.86055

[14] Jänicke, M. and Lindemann, S. (2010) Governing Environmental Innovations. Environmental Politics, 19, 127-141. https://doi.org/10.1080/09644010903396150

[15] Shuai, C., Chen, X., Wu, Y., Zhang, Y. and Tan, Y. (2019) A Three-Step Strategy for Decoupling Economic Growth from Carbon Emission: Empirical Evidences from 133 Countries. Science of the Total Environment, 646, 524-543. https://doi.org/10.1016/j.scitotenv.2018.07.045

[16] Knight, K.W. and Rosa, E.A. (2011) The Environmental Efficiency of Well-Being: A Cross-National Analysis. Social Science Research, 40, 931-949. https://doi.org/10.1016/j.ssresearch.2010.11.002

[17] Steinberger, J.K. and Roberts, J.T. (2010) From Constraint to Sufficiency: The De- 
coupling of Energy and Carbon from Human Needs, 1975-2005. Ecological Economics, 70, 425-433. https://doi.org/10.1016/j.ecolecon.2010.09.014

[18] Sweidan, O.D. (2018) Economic Performance and Carbon Intensity of Human Well-Being: Empirical Evidence from the MENA Region. Journal of Environmental Planning and Management, 61, 699-723. https://doi.org/10.1080/09640568.2017.1332986

[19] Jorgenson, A.K. and Givens, J. (2015) The Changing Effect of Economic Development on the Consumption-Based Carbon Intensity of Well-Being, 1990-2008. PLoS ONE, 10, e0123920. https://doi.org/10.1371/journal.pone.0123920

[20] Yangka, D., Newman, P., Rauland, V. and Devereux, P. (2018) Sustainability in an Emerging Nation: The Bhutan Case Study. Sustainability, 10, 1622. https://doi.org/10.3390/su10051622

[21] Thinley, J.Y. (2005) What Does Gross National Happiness (GNH) Mean? Rethinking Development: 2nd International Conference on GNH, Halifax, 20-24 June 2005, 3-11.

[22] CBS (2016) A Compass Towards a Just and Harmonious Society: 2015 GNH Survey Report. Centre for Bhutan Studies \& GNH Research, Thimphu Bhutan.

[23] Rogelj, J., Schaeffer, M., Meinshausen, M., Knutti, R., Alcamo, J., Riahi, K. and Hare, W. (2015) Zero Emission Targets as Long-Term Global Goals for Climate Protection. Environmental Research Letters, 10, Article ID: 105007. https://doi.org/10.1088/1748-9326/10/10/105007

[24] Allison, E. (2012) Gross National Happiness. In: Spellerberg, I., Ed., The Berkshire Encyclopedia of Sustainability: Measurements, Indicators, and Research Methods for Sustainability, Berkshire Publishing Group, Great Barrington, 180-184.

[25] Brooks, J.S. (2013) Avoiding the Limits to Growth: Gross National Happiness in Bhutan as a Model for Sustainable Development. Sustainability, 5, 3640-3664. https://doi.org/10.3390/su5093640

[26] Frame, B. (2005) Bhutan: A Review of Its Approach to Sustainable Development. Development in Practice, 15, 216-221. https://doi.org/10.1080/09614520500041963

[27] GNHC (2014) Ecological Footprint of Bhutan and Its Regions. Gross National Happiness Commission, Thimphu.

[28] Pérez-Suárez, R. and López-Menéndez, A.J. (2015) Growing Green? Forecasting $\mathrm{CO}_{2}$ Emissions with Environmental Kuznets Curves and Logistic Growth Models. Environmental Science \& Policy, 54, 428-437. https://doi.org/10.1016/j.envsci.2015.07.015

[29] York, R., Rosa, E.A. and Dietz, T. (2003) Footprints on the Earth: The Environmental Consequences of Modernity. American Sociological Review, 68, 279-300. https://doi.org/10.2307/1519769

[30] Dietz, T., Rosa, E.A. and York, R. (2009) Environmentally Efficient Well-Being: Rethinking Sustainability as the Relationship between Human Well-Being and Environmental Impacts. Human Ecology Review, 16, 114-123.

[31] Dietz, T., et al. (2012) Environmentally Efficient Well-Being: Is There a Kuznets Curve? Applied Geography, 32, 21-28. https://doi.org/10.1016/j.apgeog.2010.10.011

[32] Huber, J. (2004) New Technologies and Environmental Innovation. Edward Elgar, Cheltenham.

[33] Spaargaren, G. and Mol, A.P.J. (1992) Sociology, Environment, and Modernity: Ecological Modernization as a Theory of Social Change. Society \& Natural Resources, 5, 323-344. https://doi.org/10.1080/08941929209380797 
[34] Mol, A.P.J. and Spaargaren, G. (2000) Ecological Modernisation Theory in Debate: A Review. Environmental Politics, 9, 17-49. https://doi.org/10.1080/09644010008414511

[35] Panayotou, T. (1993) Empirical Tests and Policy Analysis of Environmental Degradation at Different Stages of Economic Development. International Labour Organization.

[36] Grossman, G. and Krueger, A. (1995) Economic Growth and the Environment. The Quarterly Journal of Economics, 110, 353. https://doi.org/10.2307/2118443

[37] Mardani, A., Streimikiene, D., Cavallaro, F., Loganathan, N. and Khoshnoudi, M. (2019) Carbon Dioxide $\left(\mathrm{CO}_{2}\right)$ Emissions and Economic Growth: A Systematic Review of Two Decades of Research from 1995 to 2017. Science of the Total Environment, 649, 31-49. https://doi.org/10.1016/j.scitotenv.2018.08.229

[38] Sarkodie, S.A. and Strezov, V. (2019) A Review on Environmental Kuznets Curve Hypothesis Using Bibliometric and Meta-Analysis. Science of the Total Environment, 649, 128-145. https://doi.org/10.1016/j.scitotenv.2018.08.276

[39] Song, T., Zheng, T. and Tong, L. (2008) An Empirical Test of the Environmental Kuznets Curve in China: A Panel Cointegration Approach. China Economic Review, 19, 381-392. https://doi.org/10.1016/j.chieco.2007.10.001

[40] Riti, J.S., Song, D., Shu, Y. and Kamah, M. (2017) Decoupling $\mathrm{CO}_{2}$ Emission and Economic Growth in China: Is There Consistency in Estimation Results in Analyzing Environmental Kuznets Curve? Journal of Cleaner Production, 166, 1448-1461. https://doi.org/10.1016/j.jclepro.2017.08.117

[41] Al-mulali, U., Choong, W.-W., Low, S.-T. and Mohammed, A.H. (2015) Investigating the Environmental Kuznets Curve (EKC) Hypothesis by Utilizing the Ecological Footprint as an Indicator of Environmental Degradation. Ecological Indicators, 48, 315-323. https://doi.org/10.1016/j.ecolind.2014.08.029

[42] Farhani, S., Mrizak, S., Chaibi, A. and Rault, C. (2014) The Environmental Kuznets Curve and Sustainability: A Panel Data Analysis. Energy Policy, 71, 189-198. https://doi.org/10.1016/j.enpol.2014.04.030

[43] Chow, G.C. and Li, J. (2014) Environmental Kuznets Curve: Conclusive Econometric Evidence for $\mathrm{CO}_{2}$. Pacific Economic Review, 19, 1-7. https://doi.org/10.1111/1468-0106.12048

[44] Ulucak, R. and Bilgili, F. (2018) A Reinvestigation of EKC Model by Ecological Footprint Measurement for High, Middle and Low Income Countries. Journal of Cleaner Production, 188, 144-157. https://doi.org/10.1016/j.jclepro.2018.03.191

[45] Yang, G., Sun, T., Wang, J. and Li, X. (2015) Modeling the Nexus between Carbon Dioxide Emissions and Economic Growth. Energy Policy, 86, 104-117.

https://doi.org/10.1016/j.enpol.2015.06.031

[46] Glaeser, E.L. (2011) Triumph of the City: How Our Greatest Invention Makes Us Richer, Smarter, Greener, Healthier, and Happier. Penguin Press, New York.

[47] ADB (2012) Special Chapter: Green Urbanization in Asia. In: Key Indicators for Asia and the Pacific, Asian Development Bank, Mandaluyong, 4-42.

[48] Jamel, L. and Derbali, A. (2016) Do Energy Consumption and Economic Growth Lead to Environmental Degradation? Evidence from Asian Economies. Cogent Economics \& Finance, 4, Article ID: 1170653. https://doi.org/10.1080/23322039.2016.1170653

[49] Zhang, N., Yu, K. and Chen, Z. (2017) How Does Urbanization Affect Carbon Dioxide Emissions? A Cross-Country Panel Data Analysis. Energy Policy, 107, 678-687. https://doi.org/10.1016/j.enpol.2017.03.072 
[50] Lin, S., Wang, S., Marinova, D., Zhao, D. and Hong, J. (2017) Impacts of Urbanization and Real Economic Development on $\mathrm{CO}_{2}$ Emissions in Non-High Income Countries: Empirical Research Based on the Extended STIRPAT Model. Journal of Cleaner Production, 166, 952-966. https://doi.org/10.1016/j.jclepro.2017.08.107

[51] Wang, Q., Su, M. and Li, R. (2018) Toward to Economic Growth without Emission Growth: The Role of Urbanization and Industrialization in China and India. Journal of Cleaner Production, 205, 499-511. https://doi.org/10.1016/j.jclepro.2018.09.034

[52] Schnaiberg, A. (1980) The Environment, from Surplus to Scarcity. Oxford University Press, New York.

[53] Gould, K.A., Pellow, D.N. and Schnaiberg, A. (2004) Interrogating the Treadmill of Production: Everything You Wanted to Know about the Treadmill but Were Afraid to Ask. Organization \& Environment, 17, 296-316. https://doi.org/10.1177/1086026604268747

[54] Meadows, D. and Randers, J. (2012) Limits to Growth: The 30-Year Update. Taylor \& Francis Group, Milton.

[55] Rosa, E.A. and Dietz, T. (2012) Human Drivers of National Greenhouse-Gas Emissions. Nature Climate Change, 2, 581. https://doi.org/10.1038/nclimate1506

[56] Alcott, B. (2010) Impact Caps: Why Population, Affluence and Technology Strategies Should Be Abandoned. Journal of Cleaner Production, 18, 552-560. https://doi.org/10.1016/j.jclepro.2009.08.001

[57] Waggoner, P.E. and Ausubel, J.H. (2002) A Framework for Sustainability Science: A Renovated IPAT Identity. Proceedings of the National Academy of Sciences, 99, 7860-7865. https://doi.org/10.1073/pnas.122235999

[58] Newman, P. (2011) Sustaining Our Future: Resolving the Conflict over Population Models. In: 19th International Congress on Modelling and Simulation, Modelling and Simulation Society of Australia and New Zealand Inc., Perth, 25-37.

[59] Kondoh, K. (2009) The Challenge of Climate Change and Energy Policies for Building a Sustainable Society in Japan. Organization \& Environment, 22, 52-74. https://doi.org/10.1177/1086026609333418

[60] Zhang, Z., Hao, Y., Lu, Z.-N. and Deng, Y. (2018) How Does Demographic Structure Affect Environmental Quality? Empirical Evidence from China. Resources, Conservation and Recycling, 133, 242-249. https://doi.org/10.1016/j.resconrec.2018.02.017

[61] Dietz, T. and Rosa, E.A. (1997) Effects of Population and Affluence on $\mathrm{CO}_{2}$ Emissions. Proceedings of the National Academy of Sciences, 94, 175-179. https://doi.org/10.1073/pnas.94.1.175

[62] Zhang, L., Mol, A.P.J. and Sonnenfeld, D.A. (2007) The Interpretation of Ecological Modernisation in China. Environmental Politics, 16, 659-668. https://doi.org/10.1080/09644010701419170

[63] Adua, L., York, R. and Schuelke-Leech, B.-A. (2016) The Human Dimensions of Climate Change: A Micro-Level Assessment of Views from the Ecological Modernization, Political Economy and Human Ecology Perspectives. Social Science Research, 56, 26-43. https://doi.org/10.1016/j.ssresearch.2015.10.003

[64] Rahut, D.B., Behera, B. and Ali, A. (2016) Household Energy Choice and Consumption Intensity: Empirical Evidence from Bhutan. Renewable and Sustainable Energy Reviews, 53, 993-1009. https://doi.org/10.1016/j.rser.2015.09.019

[65] Curran, G. (2018) Is Renewable Energy Still Green? Shaping Australia's Renewable Energy Enterprise in an Age of Ecological Modernisation. Environmental Politics, 
28, 950-969. https://doi.org/10.1080/09644016.2018.1510215

[66] Ramanathan, R., He, Q., Black, A., Ghobadian, A. and Gallear, D. (2017) Environmental Regulations, Innovation and Firm Performance: A Revisit of the Porter Hypothesis. Journal of Cleaner Production, 155, 79-92.

https://doi.org/10.1016/j.jclepro.2016.08.116

[67] Porter, M.E. and van der Linde, C. (1995) Green and Competitive: Ending the Stalemate. Harvard Business Review, 73, 120-134.

[68] Szigeti, C., Toth, G. and Szabo, D.R. (2017) Decoupling-Shifts in Ecological Footprint Intensity of Nations in the Last Decade. Ecological Indicators, 72, 111-117. https://doi.org/10.1016/j.ecolind.2016.07.034

[69] Schandl, H., Hatfield-Dodds, S., Wiedmann, T., Geschke, A., Cai, Y., West, J., Newth, D., Baynes, T., Lenzen, M. and Owen, A. (2016) Decoupling Global Environmental Pressure and Economic Growth: Scenarios for Energy Use, Materials Use and Carbon Emissions. Journal of Cleaner Production, 132, 45-56. https://doi.org/10.1016/j.jclepro.2015.06.100

[70] Ewing, J.A. (2017) Hollow Ecology: Ecological Modernization Theory and the Death of Nature. Journal of World-Systems Research, 23, 126-155. https://doi.org/10.5195/JWSR.2017.611

[71] Jorgenson, A.K. and Clark, B. (2012) Are the Economy and the Environment Decoupling? A Comparative International Study, 1960-2005. American Journal of Sociology, 118, 1-44. https://doi.org/10.1086/665990

[72] Jorgenson, A.K. (2014) Economic Development and the Carbon Intensity of $\mathrm{Hu}$ man Well-Being. Nature Climate Change, 4, 186-189.

https://doi.org/10.1038/nclimate2110

[73] Feng, J. and Yuan, J. (2016) Effect of Technology Innovation and Spillovers on the Carbon Intensity of Human Well-Being. Springerplus, 5, 346.

https://doi.org/10.1186/s40064-016-1984-0

[74] Greene, W.H. (2001) Econometric Software. In: Wright, J.D., Ed., International Encyclopedia of the Social \& Behavioral Sciences, Second Edition, Elsevier, Oxford, 1-7. https://doi.org/10.1016/B0-08-043076-7/02231-2

[75] IHS Global (2014) EViews 9 User's Guide I and II. IHS Global Inc., London.

[76] Yu, C. and Yao, W. (2017) Robust Linear Regression: A Review and Comparison. Communications in Statistics-Simulation and Computation, 46, 6261-6282. https://doi.org/10.1080/03610918.2016.1202271

[77] York, R., Rosa, E.A. and Dietz, T. (2003) STIRPAT, IPAT and ImPACT: Analytic Tools for Unpacking the Driving Forces of Environmental Impacts. Ecological Economics, 46, 351-365. https://doi.org/10.1016/S0921-8009(03)00188-5

[78] World Bank (2017) Bhutan Data World Bank 29 Oct 2017.

[79] Lamb, W.F., Steinberger, J.K., Bows-Larkin, A., Peters, G.P., Roberts, J.T. and Wood, F.R. (2014) Transitions in Pathways of Human Development and Carbon Emissions. Environmental Research Letters, 9, Article ID: 014011. https://doi.org/10.1088/1748-9326/9/1/014011

[80] Agung, I.G. (2010) Continuous Growth Models. In: Agung, I.G., Ed., Time Series Data Analysis Using EViews, John Wiley \& Sons, NA, 25-120.

[81] Brown, S.P.A. and McDonough, I.K. (2016) Using the Environmental Kuznets Curve to Evaluate Energy Policy: Some Practical Considerations. Energy Policy, 98, 453-458. https://doi.org/10.1016/j.enpol.2016.09.020

[82] Gujarati, D.N. (2011) Econometrics by Example. Palgrave Macmillan, Hampshire. 
[83] Suh, J. (2013) Does Buddhism Have Much to Offer in Terms of Reduction in Global $\mathrm{CO}_{2}$ Emissions? A Panel Data Analysis. Society and Economy, 35, 209-225. https://doi.org/10.1556/SocEc.35.2013.2.5

[84] O’brien, R.M. (2007) A Caution Regarding Rules of Thumb for Variance Inflation Factors. Quality \& Quantity, 41, 673-690. https://doi.org/10.1007/s11135-006-9018-6

[85] Wooldridge, M.J. (2016) Introductory Econometrics: A Modern Approach. Cengage Learning, Boston.

[86] NSB (2017) National Accounts Statistics. National Statistical Bureau, Thimphu.

[87] NSB (2004) Bhutan National Accounts Statistics. National Statistical Bureau, Thimphu.

[88] Wu, Y., Zhu, Q. and Zhu, B. (2018) Comparisons of Decoupling Trends of Global Economic Growth and Energy Consumption between Developed and Developing Countries. Energy Policy, 116, 30-38. https://doi.org/10.1016/j.enpol.2018.01.047

[89] RGoB (2018) Twelfth Five Year Plan Volume I: Main Document. Royal Government of Bhutan, Thimphu.

[90] RGoB (2010) Economic Development Policy. Royal Government of Bhutan, Thimphu.

[91] RGoB (2016) Economic Development Policy. Royal Government of Bhutan, Thimphu.

[92] World Bank (2014) Kingdom of Bhutan Green Growth Opportunities for Bhutan (Policy Note). International Bank for Reconstruction and Development, the World Bank, Danvers.

[93] NEC (1998) The Middle Path: National Environment Strategy for Bhutan. National Environment Commission, Thimphu.

[94] Toth, G. and Szigeti, C. (2016) The Historical Ecological Footprint: From OverPopulation to Over-Consumption. Ecological Indicators, 60, 283-291. https://doi.org/10.1016/j.ecolind.2015.06.040

[95] Zheng, X., Yu, Y., Wang, J. and Deng, H. (2014) Identifying the Determinants and Spatial Nexus of Provincial Carbon Intensity in China: A Dynamic Spatial Panel Approach. Regional Environmental Change, 14, 1651-1661.

https://doi.org/10.1007/s10113-014-0611-2

[96] Meng, L. and Huang, B. (2018) Shaping the Relationship between Economic Development and Carbon Dioxide Emissions at the Local Level: Evidence from Spatial Econometric Models. Environmental and Resource Economics, 71, 127-156. https://doi.org/10.1007/s10640-017-0139-2

[97] NEC (2011) Second National Communication to the UNFCCC. National Environment Commission, Thimphu.

[98] NSB and World Bank (2017) Bhutan Living Standards Survey Report 2017. National Statistical Bureau of Bhutan, Thimphu.

[99] IRP (2017) Assessing Global Resource Use: A Systems Approach to Resource Efficiency and Pollution Reduction. In: Bringezu, S., Ramaswami, A., Schandl, H., O’Brien, M., Pelton, R., Acquatella, J., Ayuk, E., Chiu, A.S.F., Flanegin, R., Fry, J., Giljum, S., Hashimoto, S., Hellweg, S., Hosking, K., Hu, Y., Lenzen, M., Lieber, M., Lutter, S., Miatto, M., Singh, A.N, Obersteiner, M., van Oers, L., Pfister, S., Pichler, P., Russell, A., Spini, L., Tanikawa, H., van der Voet, E., Weisz, West, H.W., Wijkman, A., Zhu, B. and Zivy, R., Eds., A Report by the International Resource Panel, United Nations Environment Programme, International Resource Panel, Nairobi, 100. 
[100] Glazebrook, G. and Newman, P. (2018) The City of the Future. Urban Planning, 3, 1-20. https://doi.org/10.17645/up.v3i2.1247

[101] Newman, P., Beatley, T. and Boyer, H. (2017) Resilient Cities: Overcoming Fossil Fuel Dependence. Island Press, Washington DC.

https://doi.org/10.5822/978-1-61091-686-8

[102] Wang, H. (2016) Population's Part in Mitigating Climate Change. Bulletin of the Atomic Scientists, 72, 192-193. https://doi.org/10.1080/00963402.2016.1170405

[103] Costantini, V. and Monni, S. (2008) Environment, Human Development and Economic Growth. Ecological Economics, 64, 867-880.

https://doi.org/10.1016/j.ecolecon.2007.05.011

[104] Mehta, S. (2006) Inter-Regional Variations in the Inequality and Poverty in Bhutan. Journal of Bhutan Studies, 38-42.

[105] Pearson, P. (1994) Energy, Externalities and Environmental Quality: Will Development Cure the Ills It Creates? Surrey Energy Economics Centre (SEEC), University of Surrey, Guildford. https://doi.org/10.15173/esr.v6i3.345 